\title{
Effect of applied load on welding stress at different time periods
}

\author{
Yanhu Wang ${ }^{1,2}$, Sergey Konovalov ${ }^{1, *}$, Xizhang Chen $^{1,2}$, and Irina Komissarova ${ }^{3}$ \\ ${ }^{1}$ Samara National Research University, Department of Metals Technology and Aviation Materials, \\ 443086, 34, Moskovskoye Shosse, Samara, Samara, Russia \\ ${ }^{2}$ Wenzhou University, School of Mechanical and Electrical Engineering, 325035, Chashan Education \\ Town, Wenzhou, Zhejiang, China \\ ${ }^{3}$ Siberian State Industrial University, Department of Natural Sciences, 654007, 42, Kirova str., \\ Novokuznetsk, Russia
}

\begin{abstract}
In this study, pressure finite element welding simulations has been carried out. The welding model is a butt filled weld. The objective is to study the effect of pressure on welding stress of high strength steel at different time periods. From the study we can find that no matter at the first half of welding or and the last half welding or at the cooling time apply the load have little effect to improve the stress. Only under the entire welding process that the distribution of residual stress can be greatly improved. The results show that the residual stresses of the welding workpiece under specific pressure throughout the welding process decreased by $16.2 \%$ when compared with weld group without load applied. The maximum residual stresses of weld group without load applied are more than with the specific pressure load plates $120 \mathrm{MPa}$. But under other times putting the load cannot be improved. This paper just presents a simulation results that have a certain guiding significance.
\end{abstract}

\section{Introduction}

With the development of steel production techniques, many kinds of structural steel are produced and employed in many constructions, especially like high strength steel. Due to its high strength, good ductility and notched strength, it has been wildly used around the world [1-2]. However, it has one obvious drawback that the quenching and tempering process improves the strength at the expense of ductility through complicated heat treatments. Its high strength may be weakened or eliminated by heat input. For the high strength steel, their main constitutes in the microstructures are not stable at high temperatures [3]. High-temperature processing have Influence on structure and properties [4]. Chen et al. [5-7] found that the deterioration of strength with increasing temperature was greater than that of normal strength steels. The welding is a manufacturing process and technology that joins metals or other thermoplastic materials, such as plastics, heat or pressure. And welding also has a significant impact on the strength of high strength steel.

\footnotetext{
*Corresponding author: ksv@ssau.ru
} 
Chiew et al. [3] have studied the mechanical properties of heat-treated S690 under fire/post-fire conditions. They found that $\mathrm{S} 690$ showed good resistance to low temperature (below $400{ }^{\circ} \mathrm{C}$ ) Heating, serious deterioration in strength would occur at higher temperatures. Chen et al. [8] studied the effects of welding on the tensile performance of high strength steel through a T-stub joints. They also found that welding has significant impact on the strength of high strength steel RQT-S690 T-stub joints. Liang et al. [9] through an experimental to evaluate the tension behaviour of welded high strength steel Tstub joint. They found that when the flange boundary condition close to simply supported or fixedly supported, it will have the effect on the initial stiffness of the joint.

The above is just the study of the welding temperature on the performance of highstrength steel. There is little study about the effect on the property of high strength steel applying different loads during the weld. Siddique et al. [10] studied the effect of different mechanical stress on the welding stress of the pipe. And they found that applying a radial pressure to the inside diameter of the pipe can greatly improve the residual stress. With the development of computer technology, now more and more simulations are used to observe and study welding stress and deformation in welded structures, what's more it not only can avoid expensive experimental measurements but also improve efficiency [11-13]. This paper uses the finite element analysis software to study effect of applied load on welding stress at different time periods.

\section{Experimental program}

Plates of dimensions $100 \times 50 \mathrm{~mm}$ and a thickness of $3 \mathrm{~mm}$, made of high strength steel DPW 600 are welded in the shape of a Butt fillet weld. Table 1 shows the main chemical components of the DPW 600. Firstly, simplify and clean up the established models and then mesh them. To ensure the accuracy of the premise and reduce the overall model size, the fine mesh is used near a weld where stress gradients are high, while the area far away from a weld is discretized [14-16]. The grid model is grouped and named accordingly. The 3D finite element model as shows in Fig. 1.

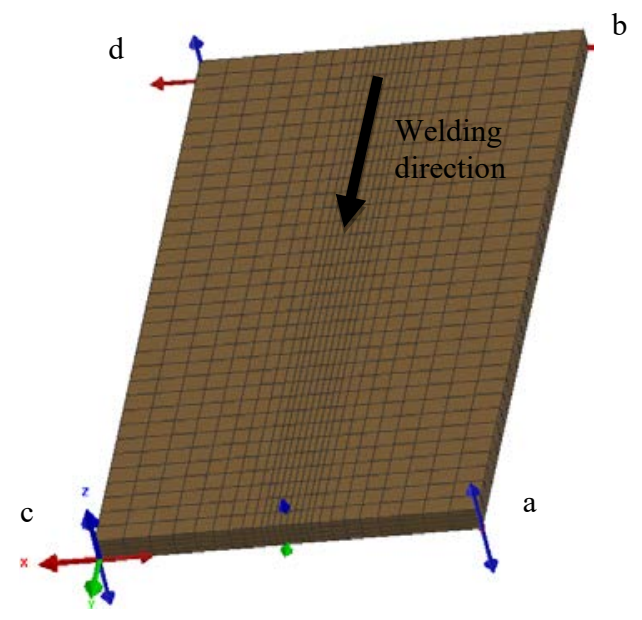

Fig. 1. Mesh of finite elements.

The boundary constraints are imposed on the model for simulation as shown in Fig. 1. Mechanical restraint in $\mathrm{Z}$ direction applied in the $\mathrm{a}$ and $\mathrm{b}$ point. Mechanical restraint in $\mathrm{X}$, $\mathrm{Y}, \mathrm{Z}$ direction applied in the c point. Mechanical restraint in $\mathrm{X}, \mathrm{Z}$ direction applied in the $\mathrm{d}$ point. The welding operation flow chart was shown in Fig. 2. TIG welding was used to 
simulate. The Welding current was $380 \mathrm{~A}$. The welding voltage was $9.2 \mathrm{~V}$ and speed was $4 \mathrm{~mm} / \mathrm{s}$. Compressive load was applied to the upper surface of the welding pieces when simulating.

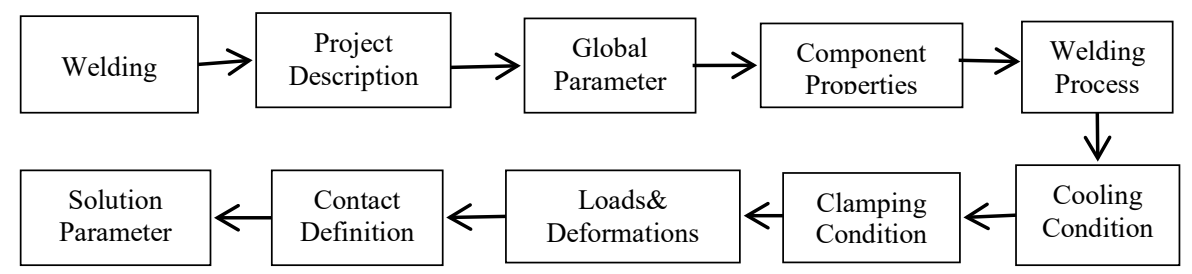

Fig. 2. Welding operation.

\section{Effect of different applied load time on stress}

In this study first to make a model for the simulation without load. The results of the Von Mises Stress are shown in Fig.3. From the Fig. 3 we can see that residual stresses are concentrated on the welding end and the maximum stress of a welded group is $542.28 \mathrm{MPa}$. Residual stresses are concentrated in the middle of the weld. In order to find the effect of different applied load time on stress. From the carbon content of the material, this material belongs to the sub-eutectoid steel. The $\mathrm{AC}_{3}$ is $867^{\circ} \mathrm{C}$. When the temperature exceeds $867^{\circ} \mathrm{C}$, the ferrite will completely form austenite. The temperature field of different time show in Fig.4. From the temperature field, 3 time points $(12.5 \mathrm{~s}, 25 \mathrm{~s}, 31.5 \mathrm{~s})$ are selected. When $31.5 \mathrm{~s}$ the temperature of the plates is $912^{\circ} \mathrm{C}$. Appling pressure load respectively during the whole welding and during the first half of the weld and during the second half of the weld and after cooling to the Ac3 temperature. So four models need to be done. they are Model 1, Model 2, Model 3 and Mode 4 respectively. The model 1 is that the pressure load time is from $0-25 \mathrm{~s}$. The model 2 exerts pressure load from $0 \mathrm{~s}$ to $12.5 \mathrm{~s}$. The model 3 exerts pressure load from $12.5 \mathrm{~s}$ to $25 \mathrm{~s}$. The model 4 exerts pressure load from $25 \mathrm{~s}$ to $31.5 \mathrm{~s}$. The results show in Fig.5, the stress of model 2 and model 3 is almost same as the model 4. And their stress distribution is similar with model without load. But the area where the maximum stress appears is not the same. The Fig. 6 shows the relationship between the maximum stress of different periods of time to exert pressure load and welding start point. Origin represents the starting point of welding. The later the pressure load is applied, the closer the maximum stress area is to the welding start point.

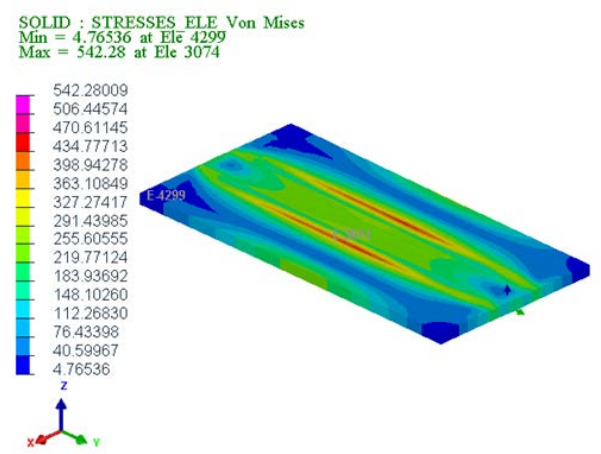

Fig. 3. Von Mises stress cloud image. 


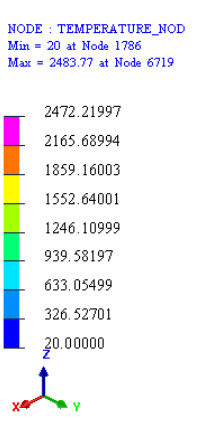

NODE : TEMPERATURE_NOD $\mathrm{Min}=45.1694$ at Node 1812
$\mathrm{Max}=3190.63$ at Node 6283

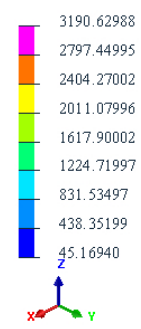

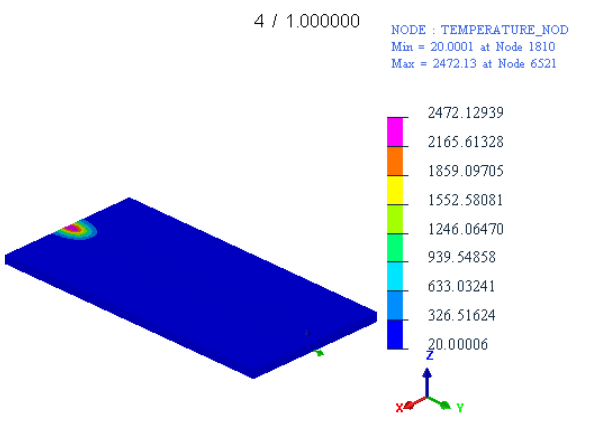

$52 / 25.000000$

NODE : TEMPERATURE_NOD Min $=211.294$ at Node 1812
$M a x=912.608$ at Node 6283

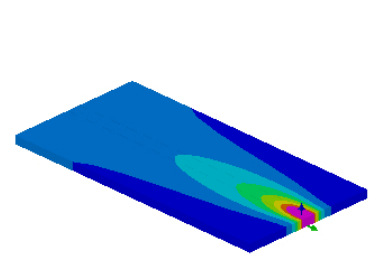

$27 / 12.500000$

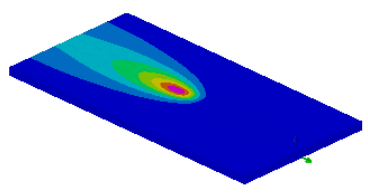

$57 / 31.593750$
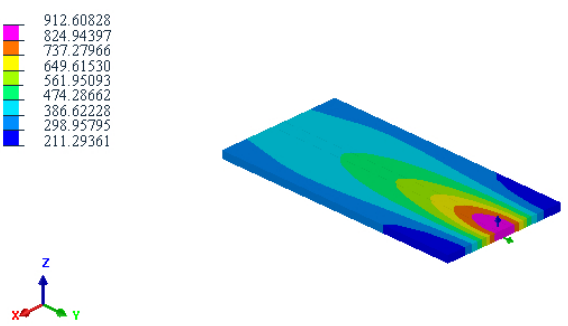

Fig. 4. The temperature field of different time.

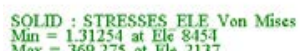

- 369.27539

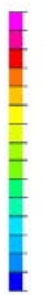

320.21368

320.21368
295.68280

246.62111

222.09026

197.55939
173.02853

148.4976

123.96683

99.43597

7490511
50.37425

50.37425
25.84340

$\frac{1.312}{2}$

$\int_{x=2}^{2}$

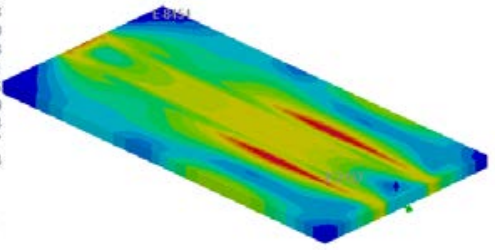

SOLID : STRESSES ELE Von Mises $\mathrm{Min}=4.73461$ at $\mathrm{kle} 845 \mathrm{I}$
$\mathrm{Max}=545.574$ at $\mathrm{Ele} 3230$

Model 3

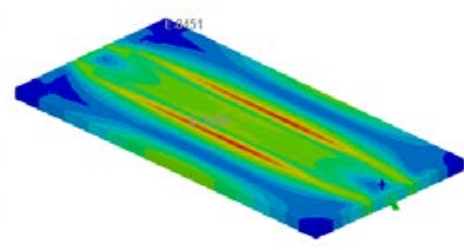

Model $1 \quad$ SOLW STRFSES EIF Von Mises

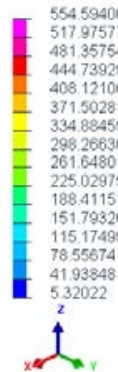

Model 2

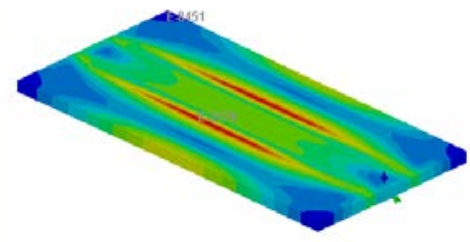

SOLID : STRESSFS ELE Von Mises
Min $=4.77195$ at $\mathrm{Ele} 845 \mathrm{I}$
$\mathrm{Max}=554.679$ at Ele 3333

Model 4

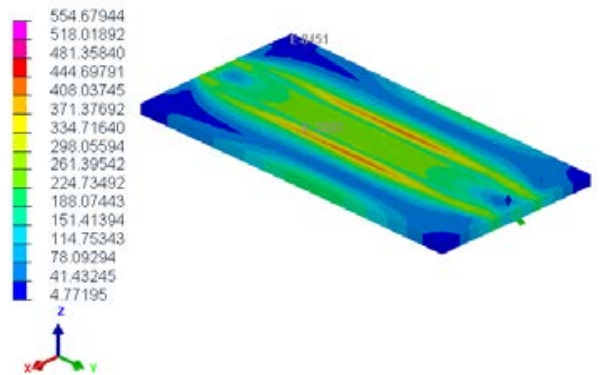

Fig. 5. Von Mises stress cloud image. 


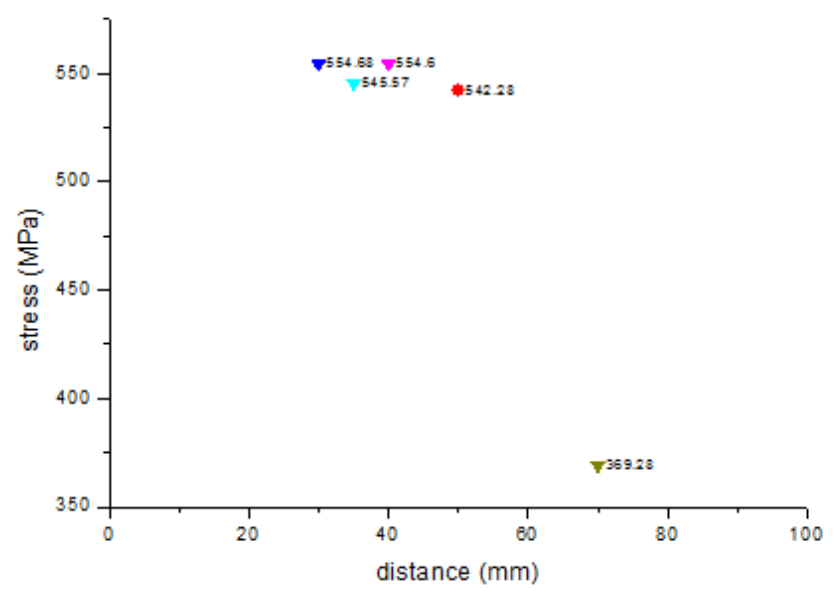

Fig. 6. The relationship between the location of maximum stress and the start of welding.

By comparing Models 2 and model 3 or model 4, it can be found that applying a compressive load during the first half of the weld or in the second half or between the end of the weld and the cooling to the Ac3 temperature can't improve the stress distribution. The location of the maximum stress is also the opposite with model 1 . Through the Martensite content at the point of Ac3, it can be find the model 1 have martensite less than others. Except for Model 1, the other models are the same in terms of austenite content when no load is applied. When cooling to the room temperature, as to all models, the Martensite content is same and unconverted Austenite content is also equal. So during welding from start to finish apply a pressure load maybe through changing the formation of austenite to improve stress distribution. Only in the first half or second half of the start of welding pressure load is not able to change the formation of austenite, which can't improve the stress distribution.

\section{Conclusion}

This paper studies the effect of different loads on welding stress of Q690 materials. It has been analyzed that the deformation, residual stress and yield strength from the simulation results. The conclusions are as follows: (1) The application of pressure load during the whole welding can improve the stress distribution; (2) Applying a pressure load in the first half or the second half of the weld is not useful for improving the stress distribution; (3) Applying a compressive load between the end of the weld to cooling to the Ac3 temperature causes the maximum stress to occur at the beginning of the weld, but without improving the stress distribution.

\section{References}

1. R. Bjorhovde. Journal of Constructional Steel Research, 60, 3 (2004).

2. R. Bjorhovde. Advances in Structural Engineering, 13, 3 (2010).

3. S.P. Chiew, M.S. Zhao, C.K. Lee. Journal of Constructional Steel Research, 98, (2014).

4. V.B. Deev, A.V. Feoktistov, I.F. Selyanin, N.I. Shvidkov, K.F. Zajnutdinov. Izvestiya Vysshikh Uchebnykh Zavedenii, Chernaya Metallurgiya, 10, (2003). 
5. J. Chen, B. Young, B. Uy. Journal of structural engineering, 132, 12 (2006).

6. X. Qiang, F. Bijlaard, H. Kolstein. Construction and Building Materials, 30, (2012).

7. X. Qiang, F.S. Bijlaard, H. Kolstein. Materials \& Design, 40, (2012).

8. C. Chen, X. Zhang, M. Zhao, C.K. Lee, T.C. Fung, S.P. Chiew. In Structures, 9, (2017).

9. G. Liang, H. Guo, Y. Liu, Y. Li. Thin-Walled Structures, 122, (2018).

10. M. Siddique, M. Abid. Modelling and Simulation in Materials Science and Engineering, 13,8 (2005).

11. Z. Chen, Z. Chen. Ajit Shenoi, R. Ocean Eng. 106, (2015).

12. B.G. Zhang, J. Zhao, X. Peng, G.Q. Chen. Appl. Therm. Eng. 80, (2015),

13. J. Shen, Z.J. Chen. Mater. Process. Technol. 214, 11 (2014).

14. M.S. Zhao, S.P. Chiew, C.K. Lee. J Constr Steel Res 122, (2016).

15. Y.H. Wang, X.Z. Chen. TIWM, 2, (2018).

16. S. Konovalov, X. Chen, V. Sarychev, S. Nevskii, V. Gromov, M. Trtica. Metals, 7, 1 (2017). 